\title{
Role of downregulation of galectin-9 in the tumorigenesis of gastric cancer
}

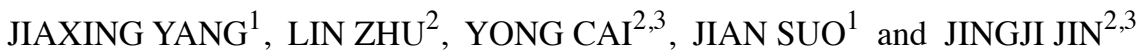 \\ ${ }^{1}$ Department of Gastrointestinal Surgery, The First Hospital of Jilin University, Changchun, Jilin 130021; \\ ${ }^{2}$ School of Life Sciences, ${ }^{3}$ Key Laboratory for Molecular Enzymology and Engineering, \\ The Ministry of Education, Jilin University, Changchun, Jilin 130012, P.R. China
}

Received March 28, 2014; Accepted May 21, 2014

DOI: $10.3892 /$ ijo.2014.2494

\begin{abstract}
Galectin-9 (Gal-9), a member of the $\beta$-galactosidebinding galectin family, plays a role in immune response, apoptosis, cell proliferation and cell death. Recent studies have shown that abnormal expression of Gal-9 is involved in certain primary cancers. The present study is the first investigation of the role of Gal-9 gene expression in clinically diagnosed primary gastric cancer tissues. Gal-9 mRNA expression was assessed in 44 clinically diagnosed frozen primary cancer tissue samples using quantitative PCR (qPCR). Analysis of the qPCR data revealed a significant reduction ( $>2$-fold decreased) of Gal-9 gene expression in gastric cancer tissues in $77 \%$ (34/44) of patients. In patients with gastric cancer, although no statistically significant difference was found between adjacent $(<2 \mathrm{~cm}$ away from the cancer tissue) and normal tissues ( $>5 \mathrm{~cm}$ away from the cancer tissue), a $>2$-fold reduction in $\mathrm{Gal}-9$ expression was observed in the adjacent tissues of $34 \%$ of the patients. Compared to matched normal or adjacent tissues, the gene expression of Gal-9 was significantly decreased in tumor tissues $(\mathrm{p}<0.001)$. The correlation of Gal-9 expression and clinicopathological features in gastric cancer was analyzed according to the TNM classification system using AJCC stage grouping. In patients with gastric cancer, clinical staging, tumor pathological stage (pT stage), tumor cell differentiation, lymph node metastasis and survival rate were found to be associated with Gal-9 expression. However, no significant association was found between Gal-9 expression and distant metastasis ( $\mathrm{p}>0.05)$. No significant difference
\end{abstract}

Correspondence to: Professor Jian Suo, Department of Gastrointestinal Surgery, The First Hospital of Jilin University, Changchun, Jilin 130021, P.R. China

E-mail: suojian42@gmail.com

Professor Jingji Jin, School of Life Sciences, Jilin University, 2699 Qianjin Street, Changchun, Jilin 130012, P.R. China

E-mail: jjjin@jlu.edu.cn

Key words: gastric cancer, galectin-9, Tim-3, gene expression was found between patients of different genders, levels of cell differentiation, distant metastasis status or different survival time of patients. Compared to normal tissues, $>2$-fold reduction of Tim-3 expression in gastric cancer tissues occurred in $59 \%$ of patients, but no correlation was found between Gal-9 and Tim-3 in gastric cancer. These results strongly suggest that Gal-9 is involved in tumorigenesis of gastric cancer.

\section{Introduction}

Galectins have been characterized based on their $\beta$-galactosidebinding affinity, and their proteins have an evolutionarily conserved carbohydrate recognition domain (CRD) $(1,2)$. Galectin family proteins can be classified by structure into three subtypes: chimeric galectin, prototype galectin, and tandem-repeat galectin $(3,4)$. Galectin-9 (Gal-9), as a tandemrepeat galectin, was first identified in a patient with Hodgkin's disease (5). The structure of Gal-9 is similar to that of other members of the galectin family, such as galectin-4 and galectin-8, which contained two homologous CRD domains separated by a linker peptide $(6,7)$. There are three isoforms of Gal-9. Based on the size of the linker peptide connecting two CRDs, they were named long-sized Gal-9 (Gal-9L), mediumsized Gal-9 (Gal-9M), and short-sized Gal-9 (Gal-9S) (8). All these isoforms are transcriptionally active and protein-coding (9), but little is known about their differences in cellular functions. Research has revealed that overexpression of Gal-9L decreased E-selectin levels, while Gal-9M or Gal-9S increased E-selectin levels in LoVo cells, suggesting three different isoforms of Gal-9 might exert distinct biological functions (10).

Increasing amounts of evidence suggest that Gal-9 has a variety of biological functions. Experimental results have shown that Gal-9 induces apoptosis when added to various types of cells, such as T-cells and different types of leukemia cells $(11,12)$. Gal-9-induced apoptosis may be associated with the $\mathrm{Ca}^{2+}$-calpain-caspase-1 pathway and Jun $\mathrm{NH}_{2}$-terminal kinase (JNK) and/or p38 MAPK signaling pathways $(13,14)$. Previous results have shown the involvement of Gal-9 in tumor cell adhesion, aggregation, and proliferation. For example, high levels of Gal-9 expression in melanoma and MCF-7 cells causes formation of colonies and clusters, but cells that lack Gal-9 expression do not $(11,15)$. Further studies 
have confirmed that abnormal expression of Gal-9 is involved in the regulation of cell adhesion and aggregation. This view was supported by findings reported by Zhang et al, who observed that the loss of Gal-9 in hepatocellular carcinoma cells in vitro increased the activity of adhesion and invasion of these cells (16).

Marked differences were found between Gal-9 expression in cancer and in normal tissues. Differential Gal-9 protein expression was observed in different tumor tissues. Gal-9 protein was strongly and homogeneously expressed in melanocytic nevi but downregulated in melanoma cells, especially in metastatic lesions. High levels of Gal-9 expression are inversely correlated with the progression of primary melanoma lesions (11). However, the lack of Gal-9 expression was correlated with distant metastasis in a majority of patients with breast cancer (15). Similarly, Gal-9 was evidently detected in normal epithelium and endocervical glands, but those in cervical intraepithelial neoplasia and cervical squamous cell carcinoma cells were significantly faint (17). To be clear, so far, the expression of Gal-9 in tumor tissues has only been investigated in limited types of tumors, and all experiments are based on histochemical staining to determine the expression level of Gal-9 as an indicator. Here, we first measured Gal-9 gene expression levels in clinically diagnosed primary gastric cancer tissues by quantitative PCR (qPCR) and the relationship between mRNA expression levels of Gal-9 and clinicopathological features in gastric cancer was analyzed. The correlation between Gal-9 and Tim-3 was also assessed in gastric cell lines.

\section{Materials and methods}

Tissue collection. Forty-four patients with primary gastric cancer were enrolled in this study. All patients underwent radical surgery between September 2008 and July 2013 at the First Hospital of Jilin University and did not receive any adjuvant therapy before the surgical operation. Gastric cancer and corresponding adjacent $(<2 \mathrm{~cm}$ away from the tumor area) and normal tissues ( $>5 \mathrm{~cm}$ away from the tumor area) were collected from patients. The median age of the patients was 64 years (range 44-84 years). Written informed consent was obtained from all participants, and the study was approved by the Institutional Ethics Board of the School of Medicine, Jilin University. Medical records of the patients, including age and gender, tumor staging, pathological diagnosis, and surgical records were reviewed. Tumors were staged according to the 2010 TNM classification system using the American Joint Committee on Cancer (AJCC) stage grouping (18).

Antibodies. Anti-Galectin-9 (17938-1-AP) and anti-Tim-3 (11872-1-AP) polyclonal antibodies were purchased from Proteintech Group (Wuhan, China). Anti-GAPDH was raised against bacterially expressed proteins (Jilin University, Changchun, China).

Construction of galectin-9 (Gal-9) expression plasmids. Expression vectors for human Gal-9 were constructed by inserting cDNA into the XhoI/BamHI sites of pcDNA3.1(-). The integrity of the DNA sequence was confirmed by DNA sequencing (GenBank accession no. BAB83624).
Reverse transcription PCR (RT-PCR). Total RNA from gastric cancer, adjacent, and normal tissues was isolated using TRIzol ${ }^{\circledR}$ LS reagent (Invitrogen, CA, USA). Then, $1 \mu \mathrm{g}$ of total RNA from each sample was used as a template to produce cDNA with a PrimeScript 1st Strand cDNA Synthesis kit (Takara, Dalian, China). Human Gal-9, Tim3 and GAPDH mRNA levels were analyzed using quantitative PCR (qPCR) with an Eco Real-Time PCR system (Illumina, CA, USA). All PCR reactions were finished as follows: initial denaturation step at $95^{\circ} \mathrm{C}$ for $30 \mathrm{sec}$, followed by 40 cycles of denaturation at $95^{\circ} \mathrm{C}$ for $5 \mathrm{sec}$, annealing at $60^{\circ} \mathrm{C}$ for $30 \mathrm{sec}$, and extension at $72^{\circ} \mathrm{C}$ for $30 \mathrm{sec}$. Primer sets used for PCR were as follows: Gal-9, 5'-CTTTCATCACCACCATTCTG-3' (forward) and 5'-ATGTGGAACCTCTGAGCACTG-3' (reverse). This pair of primers can detect three different isoforms of Gal-9 and produce a 91 -bp product; $\beta$-actin, 5'-ATGGGTCAGAAGGAT TCCTATGT-3' (forward) and 5'-AGCCACACGCAGCTC ATT-3' (reverse) produce a 153-bp product. Tim-3, 5'-CAGAT ACTGGCTAAATGGG-3' (forward) and 5'-CTTGGCTG GTTTGATGAC-3' (reverse) produce a 160 -bp product.

Cell culture and transient transfection. Human gastric cancer cell lines SGC-7901 and MGC-803 were obtained from Department of Gastrointestinal Surgery, First Hospital of Jilin University. Human gastric mucosal cell line GES-1 was provided by the Cancer Hospital of Beijing University. Cells were cultured in Dulbecco's modified Eagle's medium (DMEM, Sigma-Aldrich, St. Louis, MO, USA) with 5\% glucose and $10 \%$ fetal bovine serum (FBS), $100 \mathrm{U} / \mathrm{ml}$ penicillin, and $100 \mathrm{mg} / \mathrm{ml}$ streptomycin in $10-\mathrm{cm}$ dishes at $37^{\circ} \mathrm{C}$ in a humidified atmosphere of $5 \% \mathrm{CO}_{2}$. For transient transfection, cells were cultured in 6 -well tissue culture plates $\left(\sim 2.5 \times 10^{5}\right.$ cells/ well) in DMEM medium containing $10 \%$ fetal bovine serum. Then cells were transfected with Gal-9 cDNAs. After $48 \mathrm{~h}$ of transfection, cells were harvested and lysed for western blotting and total RNA isolation.

Preparation of whole cell extracts and western blotting (WB). First, $100 \mathrm{mg}$ of gastric cancer, adjacent or normal tissue samples were homogenized with liquid nitrogen and solubilized in $200 \mu \mathrm{l}$ cold PBS containing $1.0 \%$ Nonidet P-40, $0.5 \%$ Na-deoxycholate, $0.1 \%$ SDS, $0.05 \mathrm{mM}$ PMSF and protease inhibitor cocktail. The homogenate was swirled and kept on ice for $30 \mathrm{~min}$. Whole-cell extracts were sonicated (Scientz-IID, Ningbo, China) for $10 \mathrm{sec}$ with $50 \%$ initial cycle and centrifugation at 13,000 x g for $30 \mathrm{~min}$. Equal total amounts of protein from tissue whole-cell lysates were mixed with 4X SDS-containing sample buffer and boiled for $5 \mathrm{~min}$ at $95^{\circ} \mathrm{C}$. Proteins were then separated by $12 \%$ SDS-PAGE. Specific proteins were detected by WB using Galectin-9, Tim-3, and GAPDH polyclonal antibodies.

Statistical analysis. The western blot images were scanned and quantified with Quantity One Basic software (Bio-Rad, USA). Differences in gene and protein expression between tumor and normal tissues or tumor and adjacent tissues or adjacent and normal tissues were statistically analyzed using SPSS 17.0 (SPSS, Inc., Chicago IL, USA). Statistical comparisons were analyzed using the Student's t-test. Values of $\mathrm{p}<0.05$ were considered statistically significant. 
A

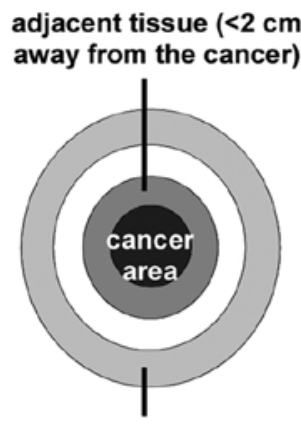

normal tissue $(>5 \mathrm{~cm}$ away from the cancer)
B

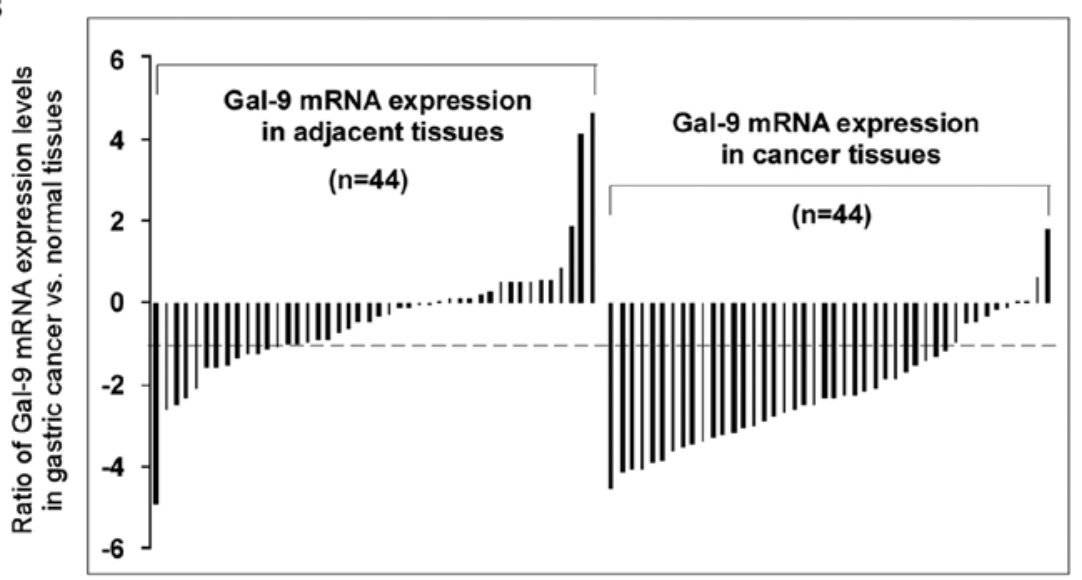

C

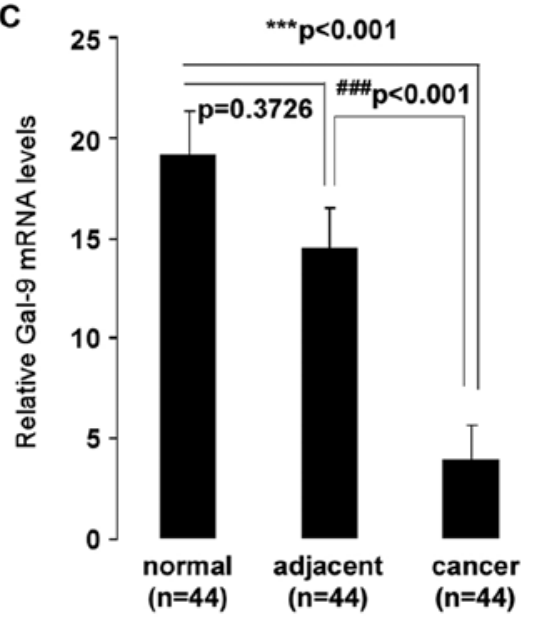

D

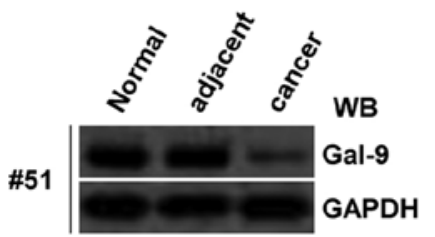

\#45

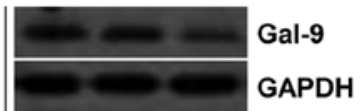

\#9

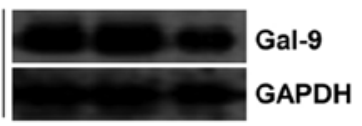

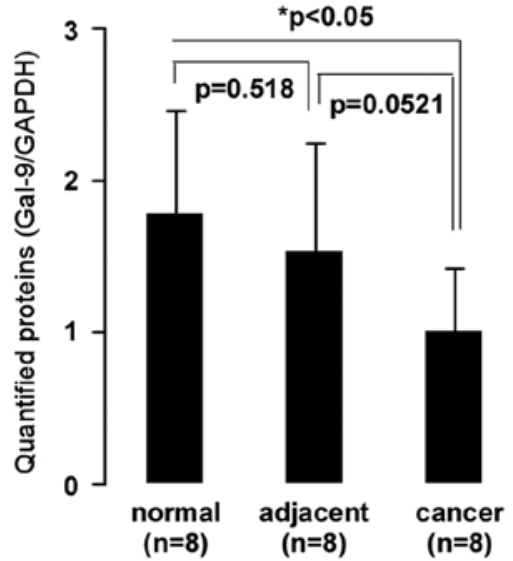

Figure 1. Downregulation of Gal-9 in gastric cancer tissues. Total RNA was isolated using TRIzol from 44 corresponding gastric cancer, adjacent, and normal tissues. (A) Tissue samples: cancer area, the site of pathologically diagnosed gastric cancer; adjacent tissue, $<2 \mathrm{~cm}$ away from the tumor in which the cells were pathologically normal; normal tissue, $>5 \mathrm{~cm}$ away from the cancer. (B) Patterns of expression of $\mathrm{Gal}-9 \mathrm{mRNA}$ in gastric cancer tissues. mRNA expression levels of Gal-9 in clinically diagnosed gastric cancer and matched adjacent/normal tissues were detected by qPCR. y-axis displays a ratio of expression of Gal-9 in gastric cancer or adjacent versus matched normal tissues. Each bar is the log2 value of the ratio of Gal-9 expression levels between gastric cancer or adjacent and matched normal tissues from the same patients. Bar value $>1$ represents $>2$-fold increases, and bar value $<-1$, represents $>2$-fold decreases. (C) Relative mRNA expression levels of Gal-9 in gastric cancer. Each bar represents the means of 2-3 independent replicates The significant differences between cancerous and normal tissues are expressed as ${ }^{* * *} \mathrm{p}<0.001$, and significant differences between cancerous and adjacent tissues are expressed as ${ }^{\# \# \#} \mathrm{p}<0.001$. (D) Declined in Gal-9 protein levels were detected in selected gastric cancer tissues. Whole-cell extract was prepared from 8 selected tissues, and equivalent total protein of whole cell extract was subjected to SDS-PAGE in $12 \%$ gels. Proteins were detected with western blotting with anti-Gal-9 and GAPDH antibodies. The left panel shows representative examples of western blot images were quantified using Quantity One software (Bio-Rad), and normalized by GAPDH levels (right panel). The significant difference is expressed as ${ }^{*} \mathrm{p}<0.05$.

\section{Results}

Downregulation of Gal-9 gene expression in gastric cancer. To investigate the involvement of Gal-9 gene expression in the pathogenesis of primary gastric cancer, 44 clinical gastric cancer tissues and matched adjacent $(<2 \mathrm{~cm}$ away from the tumor) and normal ( $>5 \mathrm{~cm}$ away from the tumor) tissues were used (Fig. 1A). Levels of expression of Gal-9 were measured by qPCR. Compared to matched normal or adjacent tissues, the gene expression of Gal-9 was significantly decreased in gastric cancer tissues ( $\mathrm{p}<0.001$ both) (Fig. 1C). Analysis of the mRNA expression of 44 samples showed significant $(>2$-fold decreased) downregulation of Gal-9 mRNA in 77\% (34/44) of patients, whereas $2 \%(1 / 44)$ of patients showed significant (>2-fold increased) upregulation of Gal-9. Interestingly, Gal-9 expression in adjacent tissues had also a reduction (>2-fold decrease) in 34\% (15/44) of samples (Fig. 1B). To determine whether the reduction of Gal-9 mRNA expression resulted in decreased Gal-9 protein levels, aliquots of whole cell extract from eight selected gastric cancer and corresponding normal or adjacent tissues were analyzed by western blotting with the indicated antibodies (Fig. 1D). As expected, there was significantly less Gal-9 protein in gastric cancer samples than in matched normal tissues $(\mathrm{p}<0.05)$. However, there was no significant difference between gastric cancer tissues and adjacent tissues ( $\mathrm{p}>0.05)$.

Gal-9 gene expression and clinicopathological features of gastric cancer. To expand upon the observations given above and to determine the relationship between Gal-9 gene expression and clinicopathological parameters, qPCR results were examined according to the clinical characteristics of gastric 


\section{A

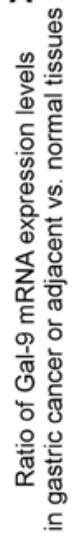

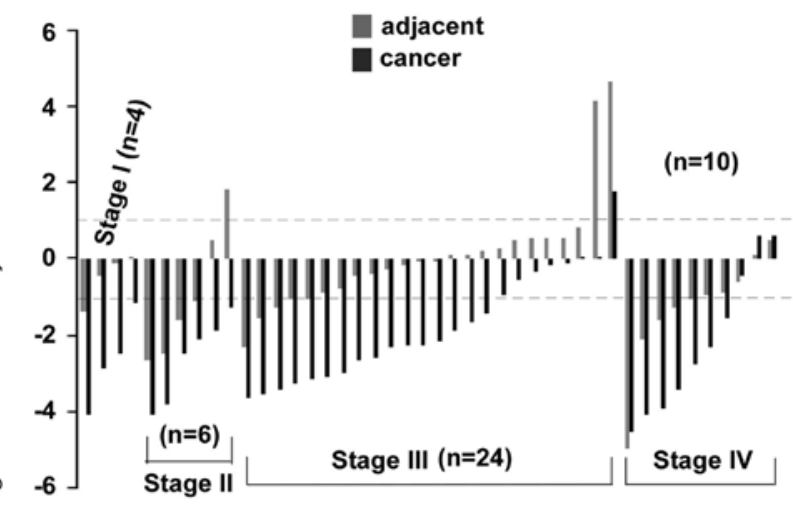

B

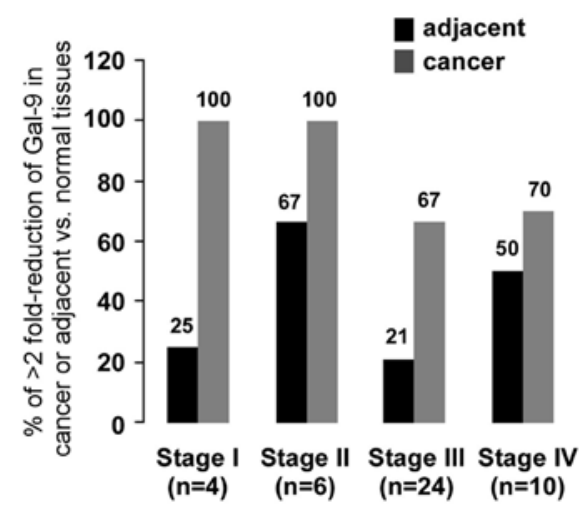

Figure 2. Gal-9 gene expression and clinical staging (stages I-IV) in gastric cancer. (A) Patterns of Gal-9 mRNA expression at different clinical stages. qPCR results were analyzed according to clinical stage. Expression is displayed as a ratio of expression of $\mathrm{Gal}$-9 in gastric cancer or adjacent versus matched normal tissues. Each bar is the $\log 2$ value of the ratio of Gal-9 expression levels between gastric cancer or adjacent and matched normal tissues from the same patients. (B) Relative amount of $>2$-fold reduction of Gal-9 mRNA expression in gastric cancer. Each bar represents the percentage of $>2$-fold reduction of Gal-9 mRNA expression in gastric cancer or adjacent vs. normal tissues.

cancer. Gastric tumors were staged according to the 2010 TNM classification system using American Joint Committee on Cancer (AJCC) stage grouping (18). A summary of clinical characteristics of the patients, including age, gender, cell differentiation, and survival, is shown in Table I. Less Gal-9 expression was observed in cancer tissues than in both normal and adjacent tissues in both the $>65$ and $\leq 65$ age groups, but the difference was significantly less pronounced in patients $\leq 65$ years than in patients $>65$ years $(\mathrm{p}<0.05)$. However, there was no significant difference by gender, cell differentiation, or survival time.

Detailed statistical analyses were performed in order to further explore the correlation between Gal-9 expression and clinical features. The correlation between Gal-9 expression and clinical staging of cancer is shown in Fig. 2. There was significantly less (>2-fold) Gal-9 mRNA than in normal tissues in $100 \%$ (4/4) of stage I, in 100\% (6/6) of stage II, in $67 \%(16 / 24)$ of stage III and 70\% (7/10) of stage IV. After statistical analysis for clinical staging (data not shown), significantly less Gal-9 mRNA than in normal tissues was observed only in stage III gastric tumors $(n=24, p<0.01)$.

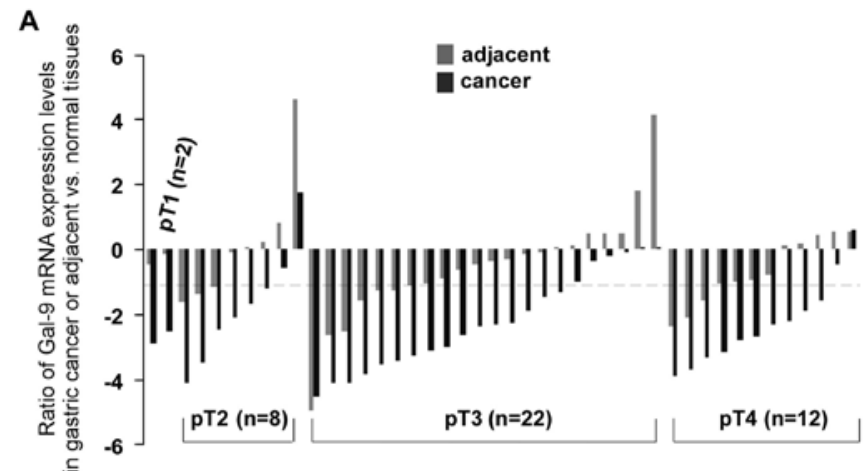

B

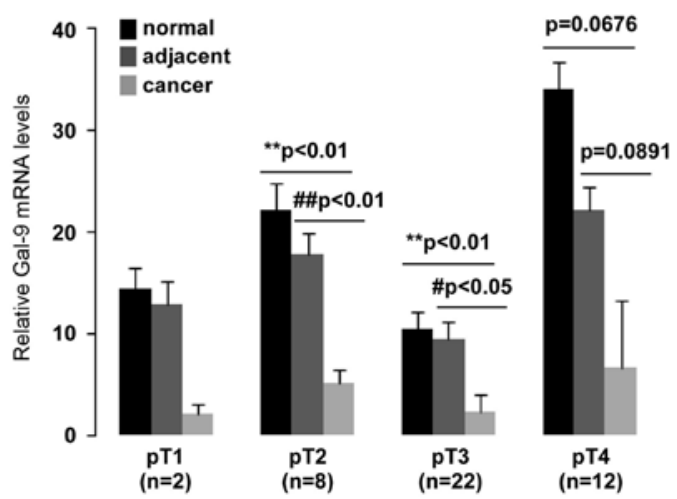

Figure 3. Gal-9 gene expression and pathological staging (pT stage) in gastric cancer. (A) Gal-9 mRNA expression patterns in different pathological pT stages. qPCR results were analyzed according to pathological stage. The $\log 2$ value of the ratio of $\mathrm{Gal}-9$ expression levels between gastric cancer or adjacent and matched normal tissues from the same patients are shown in the y-axis. (B) Relative levels of Gal-9 mRNA at different pathological pT stages. Significant differences between cancer and normal tissues are expressed as ${ }^{* *} \mathrm{p}<0.01$, and significant differences between cancer and adjacent tissues are expressed as ${ }^{\#} \mathrm{p}<0.05,{ }^{\# \#} \mathrm{p}<0.01$.

Analysis of the pathological stage showed significantly low levels of Gal-9 expression in pT2- and pT3-stage gastric cancer compared to normal $(\mathrm{p}<0.01)$ or adjacent $(\mathrm{p}<0.01$ and $\mathrm{p}<0.05$, respectively) tissues (Fig. 3B). A $>2$-fold reduction of Gal-9 mRNA was found in 75\% (6/8) of pT2 and $73 \%(16 / 22)$ of pT3 (Fig. 3A). qPCR data were also analyzed based on adjacent lymph node metastasis and distant metastasis. A significant downregulation of Gal-9 mRNA in N2 $(p<0.05)$ and $\mathrm{N} 3(\mathrm{p}<0.001)$ of lymph node metastasis groups was observed (Fig. 4A). Despite the remarkably decrease in Gal-9 expression in patients with gastric cancer, no statistically significant difference was not found between with or without metastasis groups (Fig. 4B). In addition, a significant observation was discovered in the Gal-9 expression (Fig. 4C and D). Low levels of Gal-9 mRNA expression were observed in patients who survived for less $(p<0.01)$ or more $(\mathrm{p}<0.01)$ than one year. Of all patients evaluated here, $66 \%$ survived less than one year.

Gal-9 and Tim-3 in gastric cancer. Gal-9 has been identified as a Tim-3 ligand and the binding of Gal-9 to Tim-3 induces cell death in Th1 cells (19). In order to assess the correlation between Gal-9 and Tim-3 in gastric cancer, Tim-3 gene expression was examined in 44 paired clinically diagnosed primary 
Table I. Relationship between hGal-9 gene expression (qPCR) and clinicopathological characteristics of gastric cancer.

\begin{tabular}{|c|c|c|c|c|c|c|c|}
\hline Factor & $\begin{array}{l}\text { Case } \\
(\mathrm{n})\end{array}$ & $\begin{array}{c}\text { Normal } \\
\text { mean } \pm \mathrm{SD}\end{array}$ & $\begin{array}{c}\text { Adjacent } \\
\text { mean } \pm \mathrm{SD}\end{array}$ & $\begin{array}{c}\text { Cancer } \\
\text { mean } \pm \mathrm{SD}\end{array}$ & $\begin{array}{c}\text { p-value } \\
\text { nor vs. adj }\end{array}$ & $\begin{array}{c}\text { p-value } \\
\text { nor vs. can }\end{array}$ & $\begin{array}{c}\text { p-value } \\
\text { adj vs. can }\end{array}$ \\
\hline All & 44 & $19.1 \pm 2.23$ & $14.5 \pm 2.07$ & $3.99 \pm 1.69$ & 0.373 & $0.000477^{\mathrm{c}}$ & $0.000753^{\mathrm{f}}$ \\
\hline \multicolumn{8}{|l|}{ Age (years) } \\
\hline$\leq 65$ & 21 & $23.3 \pm 2.23$ & $14.4 \pm 2.11$ & $5.35 \pm 1.67$ & 0.303 & $0.0315^{\mathrm{a}}$ & $0.00389^{\mathrm{e}}$ \\
\hline$>65$ & 23 & $15.3 \pm 2.22$ & $14.6 \pm 2.05$ & $2.75 \pm 1.70$ & 0.909 & $0.00211^{\mathrm{b}, \mathrm{g}}$ & $0.0189^{\mathrm{d}}$ \\
\hline \multicolumn{8}{|l|}{ Gender } \\
\hline Male & 30 & $16.5 \pm 2.29$ & $11.1 \pm 2.06$ & $3.79 \pm 1.79$ & 0.0739 & $1.35 \mathrm{E}-05^{\mathrm{c}}$ & $5.76 \mathrm{E}-05^{\mathrm{f}}$ \\
\hline Female & 14 & $24.7 \pm 2.08$ & $21.9 \pm 2.14$ & $4.43 \pm 1.48$ & 0.857 & 0.118 & $0.0415^{\mathrm{d}}$ \\
\hline \multicolumn{8}{|l|}{ Differentiation } \\
\hline Well & 2 & $10.3 \pm 1.95$ & $10.6 \pm 1.66$ & $25.1 \pm 13.0$ & 0.982 & 0.518 & 0.503 \\
\hline Moderate & 17 & $15.5 \pm 1.88$ & $12.7 \pm 1.87$ & $16.1 \pm 2.19$ & 0.579 & $0.0083^{\mathrm{b}}$ & 0.519 \\
\hline Poorly & 25 & $4.06 \pm 1.22$ & $269 \pm 1.26$ & $4.88 \pm 1.89$ & 0.461 & $0.0199^{\mathrm{a}}$ & $0.0156^{\mathrm{d}}$ \\
\hline \multicolumn{8}{|c|}{ Survival of patients } \\
\hline$>12$ months & 15 & $15.0 \pm 2.17$ & $13.9 \pm 1.99$ & $4.03 \pm 1.43$ & 0.836 & $0.00719^{\mathrm{b}}$ & $0.0195^{\mathrm{d}}$ \\
\hline$\leq 12$ months & 29 & $21.3 \pm 2.27$ & $14.9 \pm 2.13$ & $3.98 \pm 1.82$ & 0.385 & $0.00797^{\mathrm{b}}$ & $0.00726^{\mathrm{e}}$ \\
\hline
\end{tabular}

Gastric tumor compared to normal tissues; ${ }^{\mathrm{a}} \mathrm{p}<0.05 ;{ }^{\mathrm{b}} \mathrm{p}<0.01 ;{ }^{\mathrm{c}} \mathrm{p}<0.001$. Gastric tumor compared to adjacent tissues; ${ }^{\mathrm{d}} \mathrm{p}<0.05 ;{ }^{\mathrm{e}} \mathrm{p}<0.01 ;{ }^{\mathrm{f}} \mathrm{p}<0.001$. Analysis according to age group; ${ }^{\mathrm{g}} \mathrm{p}<0.05$.

A

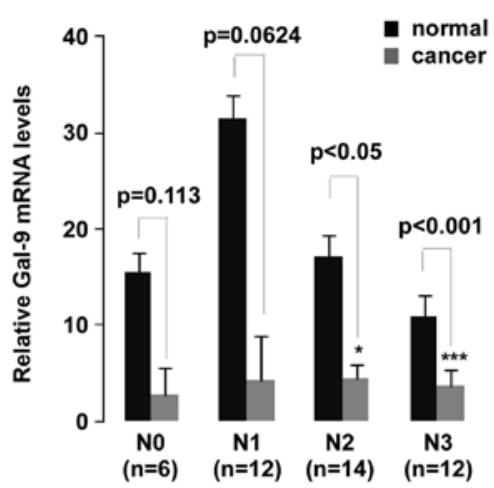

C

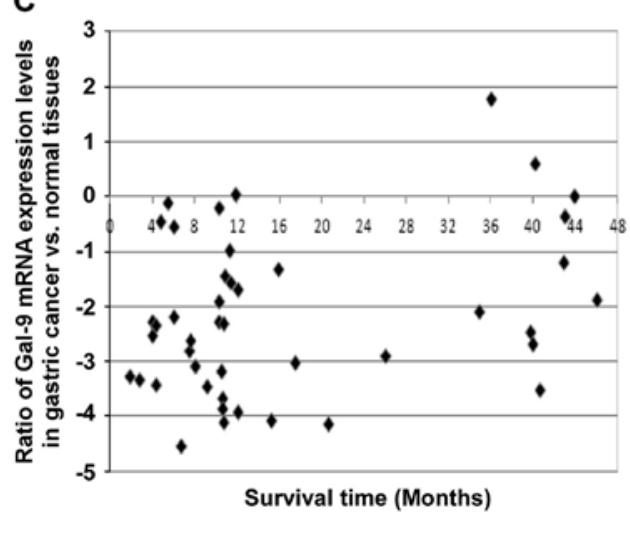

B

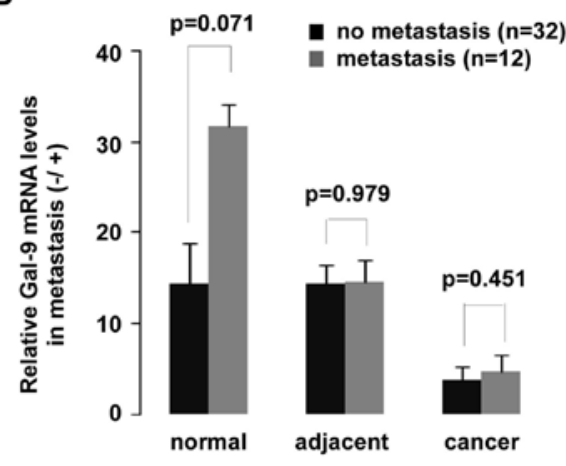

D

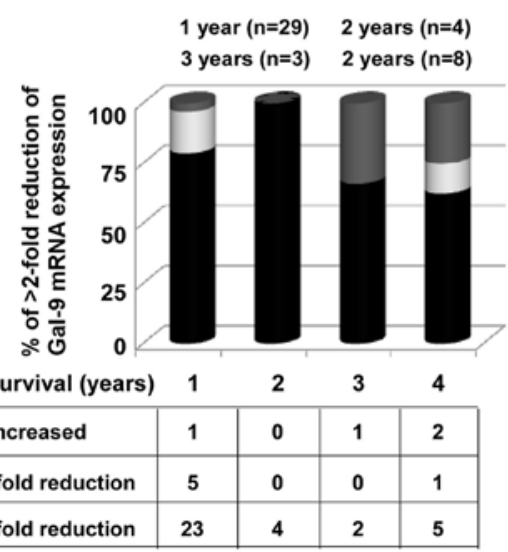

Figure 4. Gal-9 gene expression, metastasis of gastric cancer, and impact of Gal-9 gene expression levels on patient survival. (A) Statistical analysis of qPCR data according to the lymph node status. N0, no nearby lymph node metastasis; N1, 1-2 nearby lymph node metastasis; N2, 3-6 nearby lymph node metastasis; $\mathrm{N} 3,>7$ nearby lymph node metastasis. The significant difference between cancer and normal tissues is expressed as ${ }^{*} \mathrm{p}<0.05$ and ${ }^{* * * *} \mathrm{p}<0.001$. (B) Relative mRNA levels of Gal-9 with or without distant metastasis. qPCR results were analyzed according to distant metastasis of gastric cancer. (C) Levels of Gal-9 mRNA expression and patient survival. The y-axis shows the ratio of expression of Gal-9 in gastric cancer versus matched normal tissues. The x-axis shows patient survival in months. (D) Differences in Gal-9 mRNA expression in patients who survived for different lengths of time. The $100 \%$ stacked column charts are here used to compare the numbers of cases of differentially expressed Gal-9 mRNAs. The total numbers of cases of differentially expressed mRNAs (increase, $<2$-fold reduction and $>2$-fold reduction) in gastric cancer tissues represents $100 \%$. 
A

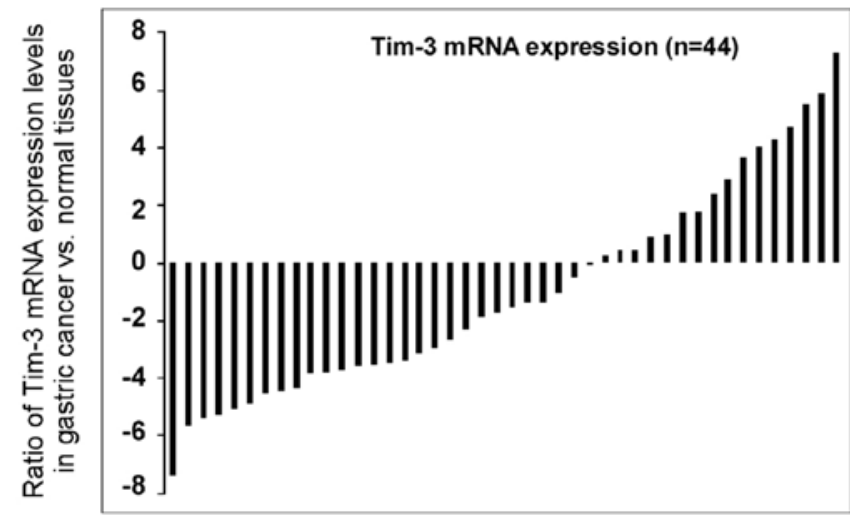

B

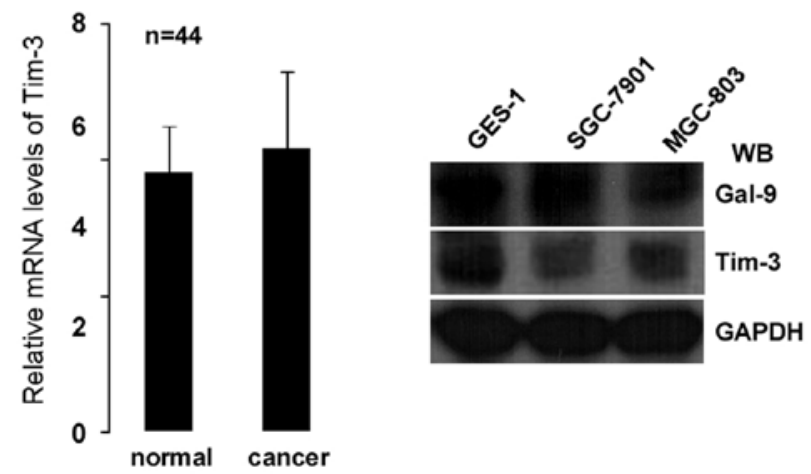

D
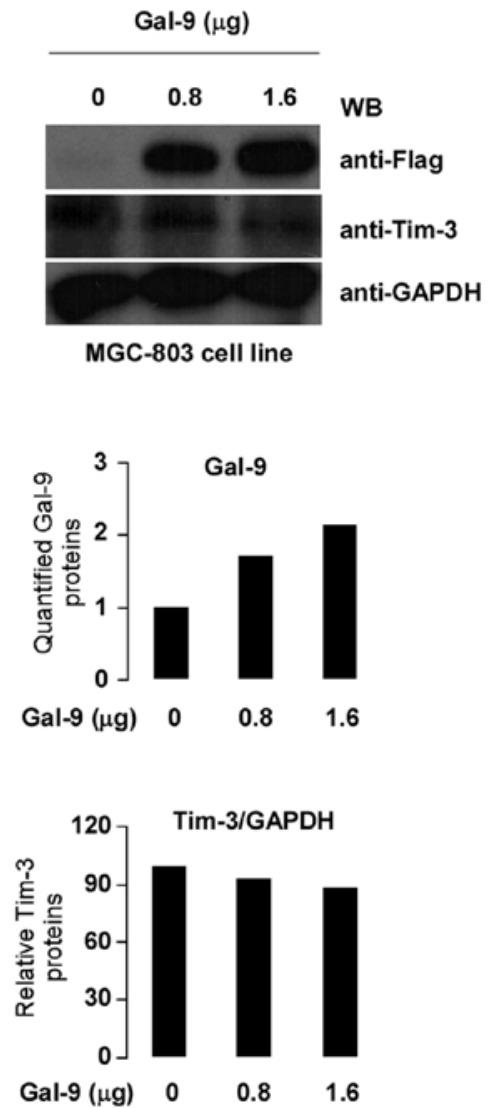

Figure 5. Gal-9 and Tim-3 in gastric cancer cells. (A) Patterns of expression of Tim-3 mRNA in gastric cancer tissues. Expression of Tim-3 mRNA in clinically diagnosed gastric cancer and matched normal tissues was detected using qPCR. The y-axis shows a log2 value of the ratio of Tim-3 expression levels between gastric cancer and matched normal tissues. (B) Relative expression of Tim-3 mRNA. (C) Levels of expression of Gal-9 and Tim-3 protein in gastric mucosal cell GES-1, and in gastric cancer cells SGC-7901 and MGC-803. Equivalent amounts of total protein from whole-cell extract were subjected to SDS-PAGE in $12 \%$ gels, and specific proteins were identified using western blot analysis with the indicated antibodies. (D) Gal-9 and Tim-3 protein expression in gastric cancer cells. MGC-803 cells were transfected with 0.8 and $1.6 \mu \mathrm{g}$ of Gal-9 cDNAs. Then, $48 \mathrm{~h}$ after transfection, cells were harvested and lysed in RIPA buffer. Equivalent amounts of total protein from whole-cell extract was subjected to 12\% SDS-PAGE and proteins were identified using the indicated antibodies (upper). Quantified Gal-9 and Tim-3 protein levels are shown in the lower panel.

gastric cancer and matched normal tissues using qPCR. As shown in Fig. 5A, cancerous tissues showed less expression of Tim-3 than in the matched normal tissues ( $>2$-fold decreased) in $59 \%$ of patients. However, Tim-3 expression was significantly increased ( $>2$-fold) in $25 \%$ of patients. Statistical analysis confirmed the absence of any significant difference between the tumor and matched normal tissues ( $\mathrm{p}>0.05)$ (Fig. 5B). To further determine whether there is any regulatory relationship between Gal-9 and Tim-3 in cells, experiments were performed using gastric cancer cell lines as models. Gal-9 and Tim-3 protein expression levels were evaluated in gastric cancer cells SGC-7901 and MGC-803 (GES-1 gastric mucosal cell as control). Fig. 5C shows the protein expression levels of Gal-9 and Tim- 3 by western blotting. To determine whether Tim-3 expression was regulated by Gal-9, MGC-803 cells were transiently transfected with 0.8 and $1.6 \mu \mathrm{g}$ of Gal-9 cDNA. Protein expression levels of Gal-9 increased dose-dependently (Fig. 5D top and middle). However, neither gene nor protein expression of Tim-3 was affected by the transient transfection of gastric cancer MGC-803 cells with Gal-9 cDNA (Fig. 5D, bottom; gene expression data not shown).

\section{Discussion}

The galectin genes are evolutionarily conserved from viruses to mammals (20). To date, 15 mammalian galectins have been identified, all of which contain one or two CRDs. Prototype galectins such as galectin-1, -2, -5, -7, -10, -11, -13 and -14 contain only one CRD. In contrast, tandem-repeat type galectins including galectin- $4,-6,-8,-9$, and -12 have two separate CRDs connected by linker peptides. Galectin-3 is the only chimeric type galectin. It contains a proline-glycine rich $\mathrm{N}$-terminal tail fused to a $\operatorname{CRD}(3,4)$. The wide distribution of galectins and the variety of binding partners led them to function in multiple biological reactions, including mRNA splicing, cell apoptosis, cell cycle regulation, cell adhesion and migration, and cell differentiation (21-24).

Galectin-9 (Gal-9) is widely distributed in tissues involved in the immune system and in tissues of endodermal origin, such as spleen, thymus, liver, intestine, and stomach tissues. Low levels of Gal-9 expression were observed in breast, lung, renal, adrenal, prostate, skin, cervical, oral, brain, ovarian, and liver cancer cell lines, but not in leukemia or colon cancer 
cell lines (4). The expression of Gal-9 in tumor tissues has only been pathologically investigated in certain limited tumor types. Research published by several groups show levels of Gal-9 expression to be lower in cancer tissues than in normal tissues $(11,15)$. These findings were consistent with the present results. In this study, the gene expression of Gal-9 was first investigated in clinically diagnosed primary gastric cancer tissues using qRT-PCR. Significant ( $>2$-fold decreased) downregulation of Gal-9 mRNA was observed in $77 \%$ (34/44) of patients with gastric cancer. It is noteworthy that the abnormal expression of Gal-9 had already appeared in adjacent tissues ( $<2 \mathrm{~cm}$ away from the cancer tissue). Compared to matched normal tissues, although no statistically significant difference was found between adjacent and normal tissues, decreased expression of Gal-9 (>2-fold) in adjacent tissues had already emerged in 34\% (15/44) of patients with gastric cancer. Loss of Gal-9 expression was found to be consistently correlated with distant metastasis $(11,15)$. The results of the present study show low levels of expression of Gal-9 mRNA to be associated with clinical staging, tumor pT stage, cell differentiation, lymph node metastasis, and patient survival. However, no significant association was observed between Gal-9 expression and distant metastasis $(\mathrm{p}=0.0616, \mathrm{p}>0.05)$. Recently, Jiang et al reported that although the Gal-9 shows pathologically higher levels of expression in gastric cancer than in normal tissues, low levels of Gal-9 expression are correlated with poor cancer prognosis (25). Combined with our findings, suggesting that low expression of Gal-9 is involved in tumorigenesis of gastric cancer.

Tim-3, a member of the T cell Ig and mucin domain (Tim) family, was found to be specifically expressed on terminally differentiated CD4 ${ }^{+}$Th1 cells, but not on Th2 cells (26). Cumulative findings indicate that the interaction of Tim-3 and its natural ligand Gal-9, exerts a crucial role in immune regulation. A recent study shows that the Tim-3/Gal-9 signaling pathway plays a critical role in the homeostasis of hepatic NKT cells through activation-induced apoptosis and secondary proliferation (27). In the present study, significantly less Tim-3 mRNA expression ( $>2$-fold) was observed in gastric cancer tissues in $59 \%$ of patients, but higher than normal expression of Tim-3 (>2-fold) was also observed in $25 \%$ of the patients. Cell experiments showed no correlation between Gal-9 and Tim-3 in gastric cancer. Further investigation might be needed to determine the functional mechanism of Tim-3/Gal-9 in gastric cancer.

In conclusion, downregulation of Gal-9 mRNA was observed in gastric cancer tissues, and statistical analysis demonstrated the molecular mechanism underlying this process. These results showed that the loss of Gal-9 expression may be involved in the progression of gastric cancers. Although the Gal-9 gene was found to be involved in gastric cancer, further studies are required to address the many remaining questions, such as the effects of alternative splicing of Gal-9 in different tumor models.

\section{Acknowledgements}

This study was supported by the Key Scientific and Technological Project of Jilin Province Science and Technology Development Program (20130206005YY).

\section{References}

1. Barondes SH, Castronovo V, Cooper DN, Cummings RD, Drickamer K, Felzi T, Gitt MA, Hirabayashi J, Hughes C, Kasai K, Leffler H, Liu FT, Lotan R,Mercurio AM, Monsigny M, Pillai S, Poirer F, Raz A, Rigby PW, Rini JM and Wang JL: Galectins: a family of animal $\beta$-galactoside-binding lectins. Cell 76: 597-598, 1994.

2. Leffler H, Carlsson S, Hedlund M, Qian Y and Poirier F: Introduction to galectins. Glycoconj J 19: 433-440, 2004.

3. Hirabayashi $\mathbf{J}$ and Kasai K: The family of metazoan metalindependent beta-galectoside-binding lectins: structure, function and molecular evolution. Glycobiology 3: 297-304, 1993.

4. Heusschen R, Griffioen AW and Thijssen VL: Galectin-9 in tumor biology: a jack of multiple trades. Biochim Biophys Acta 1836: $177-185,2013$

5. Türeci O, Schmitt H, Fadle N, Pfreundschuh M and Sahin U: Molecular definition of a novel human galectin which is immunogenic in patients with Hodgkin's disease. J Biol Chem 272: 6416-6422, 1997.

6. Oda Y, Herrmann J, Gitt MA, Turck CW, Burlingame AL, Barondes SH and Leffler H: Soluble lactose-binding lectin from rat intestine with two differentcarbohydrate-binding domains in the same peptide chain. J Biol Chem 268: 59295939, 1993.

7. Hadari YR, Paz K, Dekel R, Mestrovic T, Accili D and Zick Y: Galectin-8. A new rat lectin, related to galectin-4. J Biol Chem 27: 3447-3453, 1995.

8. Sato M, Nishi N, Shoji H, Seki M, Hashidate T, Hirabayashi J, Kasai Ki K, Hata Y, Suzuki S, Hirashima M and Nakamura T: Functional analysis of the carbohydrate recognition domains and a linker peptide of galectin-9 as to eosinophil chemoattractant activity. Glycobiology 12: 171-197, 2002.

9. Oh JH, Yang JO, Hahn Y, Kim MR, Byun SS, Jeon YJ, Kim JM, Song KS, Noh SM, Kim S, Yoo HS, Kim YS and Kim NS: Transcriptome analysis of human gastric cancer. Mamm Genome 16: 942-954, 2005.

10. Zhang F, Zheng M, Qu Y, Li J, Ji J, Feng B, Lu A, Li J, Wang M and Liu B: Different roles of galectin-9 isoforms in modulating E-selectin expression and adhesion function in LoVo colon carcinoma cells. Mol Biol Rep 36: 823-830, 2009.

11. Kageshita T, Kashio Y, Yamaguchi A, Seki M, Abedin MJ, Nishi N, Shoji H, Nakamura T, Ono T and Hirashima M: Possible role of galectin-9 in cell aggregation and apoptosis of human melanoma cell lines and its clinical significance. Int $\mathbf{J}$ Cancer 99: 809-816, 2002.

12. Lu LH, Nakagawa R, Kashio Y, Ito A, Shoji H, Nishi N, Hirashima M, Yamaguchi A and Nakamura T: Charaterization of galectin-9-induced death of Jurkat T cells. J Biochem 141: 157-172, 2007.

13. Kobayashi T, Kuroda J, Ashihara E, Oomizu S, Terui Y, Taniyama A, Adachi S, Takagi T, Yamamoto M, Sasaki N, Horiike S, Hatake K, Yamauchi A, Hirashima M and Taniwaki M: Galectin-9 exhibits anti-myeloma activity through JNK and p38 MAP kinase pathways. Leukemia 24: 843-850, 2010.

14. Kashio Y, Nakamura K, Abedin MJ, Seki M, Nishi N, Yoshida N, Nakamura T and Hirashima M: Galectin-9 induces apoptosis through the calcium-calpain-caspase-1 pathway. J Immunol 170: 3631-3636, 2003

15. Irie A, Yamauchi A, Kontani K, Kihara M, Liu D, Shirato Y, Seki M, Nishi N, Nakamura T, Yokomise H and Hirashima M: Galectin-9 as a prognostic factor with antimetastatic potential in breast cancer. Clin Cancer Res 11: 2962-2968, 2005.

16. Zhang ZY, Dong JH, Chen YW, Wang XQ, Li CH, Wang J, Wang GQ, Li HL and Wang XD: Galectin-9 acts as a prognostic factor with antimetastatic potential in hepatocellular carcinoma. Asian Pac J Cancer Prev 13: 2503-2509, 2012.

17. Liang M, Ueno M, Oomizu S, Arikawa T, Shinonaga R, Zhang S, Yamauchi A and Hirashima M: Galectin-9 expression links to malignant potential of cervical squamous cell carcinoma. J Cancer Res Clin Oncol 134: 899-907, 2008.

18. Edge SB, Byrd DR, Compton CC, Fritz AG, Greene FL and Trotti A: AJCC Cancer Staging Manual. 7th edition. Springer, Chicago, IL, 2010.

19. Zhu C, Anderson AC, Schubart A, Xiong H, Imitola J, Khoury SJ, Zheng XX, Strom TB and Kuchroo V: The Tim-3 ligand galectin-9 negatively regulates $\mathrm{T}$ helper type 1 immunity. Nat Immunol 6: 1245-1252, 2005. 
20. Cooper DN and Barondes SH: God must love galectins; he made so many of them. Glycobiology 9: 979-984, 1999.

21. Vyakarnam A, Dagher SF, Wang JL and Patterson RJ: Evidence for a role for galectin-1 in pre-mRNA splicing. Mol Cell Biol 17: 4730-4737, 1997.

22. Kuwabara I, Kuwabara Y, Yang RY, Schuler M, Green DR, Zuraw BL, Hsu DK and Liu FT: Galectin-7 (PIG1) exhibits proapoptotic function through JNK activation and mitochondrial cytochrome c release. J Biol Chem 277: 3487-3497, 2002.

23. Yang RY, Hsu DK, Yu L, Ni J and Liu FT: Cell cycle regulation by galectin-12, a new member of the galectin superfamily. J Biol Chem 276: 20252-20260, 2001

24. Elola MT, Wolfenstein-Todel C, Troncoso MF, Vasta GR and Rabinovich GA: Galectins: matricellular glycan-binding proteins linking cell adhesion, migration, and survival. Cell Mol Life Sci 64: 1679-1700, 2007.
25. Jiang J, Jin MS, Kong F, Cao D, Ma HX, Jia Z, Wang YP, Suo J and Cao X: Decreased galectin-9 and increased Tim-3 expression are related to poor prognosis in gastric cancer. Plos One 8: e81799, 2013

26. Monney L, Sabatos CA, Gaglia JL, Ryu A, Waldner H, Chernova T, Manning S, Greenfield EA, Coyle AJ, Sobel RA, Freeman GJ and Kuchroo VK: Th1-specific cell surface protein Tim-3 regulates macrophage activation and severity of an autoimmune disease. Nature 415: 536-541, 2002.

27. Tang ZH, Liang S, Potter J, Jiang X, Mao HQ and Li Z: Tim-3/ galectin-9 regulate the homeostasis of hepatic NKT cells in a murine model of nonalcoholic fatty liver disease. J Immunol 190: $1788-1796,2013$ 